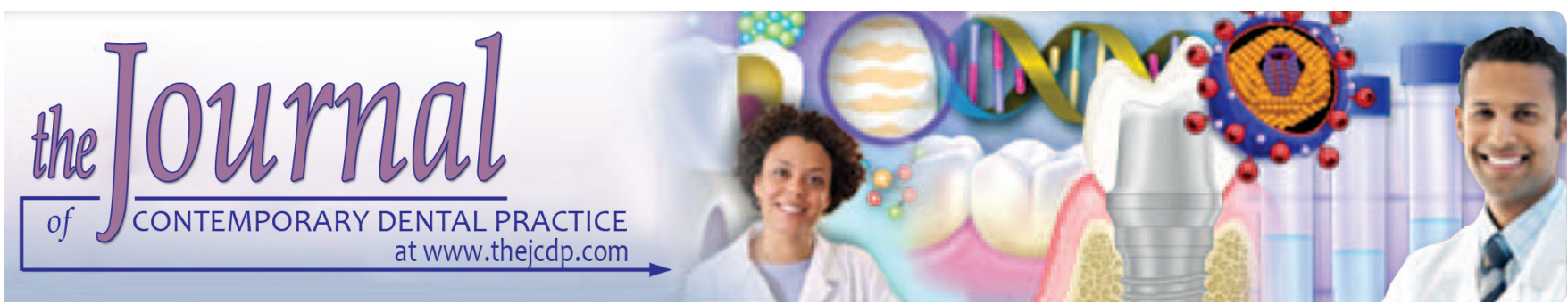

\title{
Association of Orthodontic Clear Aligners with Root Resorption Using Three-dimension Measurements: A Systematic Review
}

\author{
${ }^{1}$ Arwa Aldeeri, ${ }^{1}$ Lulu Alhammad, ${ }^{1}$ Amjad Alduham, ${ }^{1}$ Waad Ghassan, ${ }^{2}$ Sanaa Shafshak, ${ }^{3}$ Eman Fatani
}

\begin{abstract}
Aim: This paper aims to assess the evidence in the literature reporting orthodontically induced inflammatory root resorption (OIIRR) in treatment with orthodontic clear aligners using 3D measurements.

Materials and methods: Following preferred reporting Items for systematic reviews (PRISMA) statement, eight electronic databases were searched for relevant published and unpublished records. Data collected according to restricted inclusion and exclusion criteria.
\end{abstract}

Results: A total of 236 articles were identified as relevant to our topic. Duplicates were excluded resulting in 226 papers, out of which 31 papers were relevant after screening titles and abstracts. Only 2 high-level evidence papers out of the 31 met the inclusion criteria for the qualitative synthesis.

Conclusion: Based on the available studies with high level of evidence in the literature, we conclude that orthodontic clear aligners are non-inferior to light-force fixed orthodontic appliances, and superior to heavy-force fixed orthodontic appliances in terms of the risk for developing apical root resorption.

Clinical significance: Orthodontists can be more assured about the low-risk of OIIRR associated with clear aligners compared to other orthodontic treatment modalities, and it remains up to the practitioner's assessment to select the appropriate treatment on a case by case basis.

Keywords: Aligners, Orthodontic appliances, Removable, Root resorption, Systematic review.

\footnotetext{
${ }^{1}$ College of Dentistry, Riyadh Elm University, Riyadh, Kingdom of Saudi Arabia

${ }^{2}$ College of Dentistry, Preventive Department, Division of Periodontics, Riyadh Elm University, Riyadh, Kingdom of Saudi Arabia

${ }^{3}$ College of Dentistry, Preventive Department, Division of Orthodontics, Riyadh Elm University, Riyadh, Kingdom of Saudi Arabia
}

Corresponding Author: Arwa Aldeeri, College of Dentistry, Riyadh Elm University, Riyadh, Kingdom of Saudi Arabia, e-mail: arwaaldeeri@gmail.com.
How to cite this article: Aldeeri A, Alhammad L, Alduham A, Ghassan W, Shafshak S, Fatani E. Association of Orthodontic Clear Aligners with Root Resorption Using Three-dimension Measurements: A Systematic Review. J Contemp Dent Pract 2018;19(12):1559-1565.

Source of support: Nil

Conflict of interest: None

\section{INTRODUCTION}

External apical root resorption (ARR) is defined as the permanent loss of the apical part of the root structure. ${ }^{1}$ It is multifactorial in etiology, with pulpal and periodontal infection and pressure from tumors in the jaws being stimulating factors. ${ }^{2}$ It is also an unwanted consequence to orthodontic treatment, where it is called orthodontically induced inflammatory root resorption (OIIRR). ${ }^{2,3}$ Local inflammatory response induced by the application of orthodontic forces is crucial for tooth movement. However, this inflammation is the basis for OIIRR. ${ }^{4}$ For decades, this topic has been a fertile soil of research in the field of a fixed orthodontic appliance. ${ }^{5-8}$ In 1994, Hendrix et al. showed, using orthopantograms, that OIIRR was not different across genders, age groups, extraction vs. nonextraction technique and different durations of active treatment. ${ }^{5}$ In 2012 Lund et al. showed similar findings using cone beam computed tomography $(\mathrm{CBCT}) .{ }^{7}$ Other studies on OIIRR were conducted as more orthodontic systems and techniques were developed. ${ }^{7,9,10}$ In 2000, Janson et al. compared three conventional orthodontic techniques of which bio-efficient therapy was associated with less root resorption compared to simplified standard edgewise technique and edgewise straight wire system. ${ }^{6}$ Another study showed no difference between self-ligating and conventional brackets systems. ${ }^{8}$ There is compelling evidence that root resorption is worse in fixed orthodontic 
appliances using heavy forces as opposed to light forces and no intervention. ${ }^{11-13}$ Additionally, several studies evaluated root resorption in orthodontic treatment with clear aligners. ${ }^{14-16}$ A systematic review published in 2015 by Roscoe et al. assessed the association of different orthodontic force systems and root resorption, had a total of twenty-one studies with varying levels of evidence from low to high. ${ }^{9}$ Out of them, only one study studied clear aligners, showing that they are not different than lightforce fixed appliances. In 2017, Elhaddaoui et al. reported that the occurrence of OIIRR was less among patients treated with clear aligners than those treated with fixed appliances. ${ }^{17}$ However, these systematic reviews included studies that used two-dimensional measurements, which were reported to be inaccurate and inferior to threedimensional measurements. ${ }^{18}$ The current study aims to assess the available evidence in the literature about OIIRR in treatment with orthodontic clear aligners using stringent inclusion criteria addressing this concern.

\section{MATERIALS AND METHODS}

\section{Focused Question}

This systematic review was conducted to address the following focused question: "In patients who received orthodontic treatment, were orthodontic clear aligners associated with less root resorption when compared to the fixed orthodontic appliance?".

\section{Literature Search and Selection Criteria}

At first, four authors (DA, HL, DA and GW) were calibrated for intra-observer and inter-observer reliability and agreement which was conducted by one investigator (SS). Data collection and extraction were conducted by the four authors independently and any disagreement was solved by consensus or discussion with senior investigators (FE. and SS.). A total of six electronic databases were searched: Cochrane Library, Pubmed, Science Direct, Google Scholar, Saudi Digital Library (SDL) and Literatura Latino-Americana e do Caribe em Ciências da Saúde (LILACS) to identify published papers to be considered for inclusion. Unpublished work was collected via two electronic clinical trials databases: ClinicalTrials.gov and BioMed Central (ISRCTN Registry). For Cochrane Library and Pubmed, the following search sequence of medical subject headings (MeSH) terms were used "(Root Resorption and Aligners), (Removable Orthodontic Appliances and Root Resorption)". Additionally, other free text terms were used: Treatment effects, Root resorption, OIIRR, Removable appliance, Teeth positioners, Clear aligners, Invisalign ${ }^{\circledR}$, Eon aligner, BiolinerTM Plus, Clear Correct,
NuBraceTM and e-Clinger ${ }^{\circledR}$. Data collection process followed PRISMA statement (preferred reporting items for systematic reviews and meta-analyses): Identification, screening, eligibility, and inclusion. ${ }^{19}$ The selection criteria of the articles in this study are as the following:

\section{Inclusion Criteria}

- Studies written in English language.

- Publication year between 1980 and June 2017.

- Studies performed on humans.

- Studies that evaluated root resorption as an outcome of orthodontic treatment.

- Studies assessing the association of orthodontic clear aligners with root resorption.

- Studies that evaluated root resorption using threedimensional measurements, e.g., Cone Beam Computed Tomography (CBCT).

- Each study must have at least a sample size of 10 patients.

\section{Exclusion Criteria}

- Studies with a low level of evidence including but not limited to: review articles, books, case reports, case series and studies with questionnaires.

- Studies evaluated apical root resorption using twodimensional measurements (e.g., orthopantogram, periapical radiographs and/or lateral cephalogram only).

- Studies that investigated the association of orthodontic fixed appliances only with root resorption.

- Studies performed on animals.

- Studies investigated the genetic background only.

- Studies performed on patients with genetic syndromes and/or severe facial malformations.

\section{Qualitative Assessment}

The methodologic scoring system developed by Roscoe et al. was adopted to conduct the qualitative assessment for possible flaws in the design, methodology, analysis and reported findings (Table 1). ${ }^{9}$ The scoring system consisted of three main sections: study design, methodologic soundness and data analysis with a maximum total score of 21 points. A clear statement of study objectives, time direction, sample size, sample randomization, clear discerption of the selection criteria and comparison with a control group were the items based on which designs of the included studies were evaluated. Methodologic soundness of the studies was assessed based on the presence of clear description of the used appliance, applied force magnitude, and the measurement method of root resorption as well as the type of radiographic 
Table 1: The Methodologic Scoring System Adopted from Roscoe MG et al, 2015. ${ }^{9}$

\begin{tabular}{|c|c|}
\hline \multicolumn{2}{|c|}{ I. Study design (maximum score, 10 points) } \\
\hline A. Time & Retrospective, 0 point; prospective, 2 points \\
\hline B. Randomization & If stated, 1 point \\
\hline C. Control group & If present, 1 point \\
\hline D. Sample size & $\begin{array}{l}\text { Number of evaluated teeth per experimental group: }<5,1 \text { point; } 5 \text { to }=<10,2 \text { points; } .10 \text { to }=<20,3 \\
\text { points; }>20,4 \text { points }\end{array}$ \\
\hline E. Selection criteria & If clearly described, 1 point \\
\hline F. Objective & If clearly formulated, 1 point \\
\hline
\end{tabular}

II. Methodologic soundness (maximum score, 7 points)

A. Appliance type If clearly described, 1 point

B. Force magnitude If stated, 1 point; if controlled by a force measurement device, 2 points

C. Radiographic examination Periapical radiograph or cone-beam computed tomography, 1 point; other method, 0 point before treatment

D. Measurement method of Periapical radiograph or histological analysis, 1 point; SEM, TEM, CLSM, or mCT, 2 points root resorption (if 2 methods were combined, the points were summed)

III. Data analysis (maximum score, 4 points)
A. Statistical analysis
Appropriate for data, 1 point
B. Error of the method
If stated, 1 point
C. Data presentation
If $P$ value stated, 1 point
If any variability measures (standard deviation, confidence interval, or range) stated, 1 point

examination before treatment. Data analysis was examined for any errors in methods or data presentation. Based on the above assessment, every study was given a score and classified based on the level of evidence into a low level of evidence (score less than $60 \%$ of the maximum score), moderate level of evidence (score 60 to $70 \%$ ) and high level of evidence (score more than $70 \%$ ). Also, Cochrane Collaboration's Tool for Assessing Risk of Bias was applied on the eligible papers, and different forms of bias were detected including selection, performance, detection, attrition, and reporting bias. ${ }^{20}$ Accordingly, papers were considered as having a low risk of bias if scored low risk in at least four domains, moderate risk of bias if scored low risk in three domains, and high risk of bias if scored low risk in only two domains.

\section{RESULTS}

Following PRISMA statement, 236 records were identified as relevant to our topic. Excluding all duplicates, titles and abstracts of 226 collected records were screened for their relevance to the current research question. Accordingly, a total of 195 records were excluded. Afterward, the full text of each of the relevant 31 studies was assessed for its eligibility using the above-mentioned selection criteria (Flowchart 1). Two papers only were found eligible for inclusion in the qualitative synthesis, one of which was a randomized controlled trial (RCT) by Barbagallo et al. and the other as cohort study by Tylor. ${ }^{11,21}$ Evaluating the study design, the RCT and cohort papers scored 7 and 10 points, respectively (Table 2). Regarding their methodologic soundness, both papers scored 4 points with a maximum possible score of 7 (Table 3). Evaluating the data analysis, the clinical trial scored 3 points while the other scored 4 points (Table 4). The overall methodologic quality scores were $80.9 \%$ and $71.4 \%$ for the RCT and cohort, respectively, indicating that both papers have a high level of evidence $(>70 \%)$. According to Cochrane Collaboration's Tool for Assessing Risk of Bias, the RCT has a low risk of bias.11 On the other hand, the study published by Taylor J although it was of high methodologic quality, it had a high risk of bias due to lack of randomization, allocation concealment, and blinding. ${ }^{21}$ A summary of the evidence level and risk of bias assessment is presented in (Table 5).

\section{DISCUSSION}

Orthodontically induced inflammatory root resorption (OIIRR) is an adverse event that may lead to tooth loss. ${ }^{2,3}$ Although its genetic predisposition is not fully understood, the available literature suggests that OIIRR tends to be more in Whites and Hispanics than Asians, while there is no specific age nor gender predilection. ${ }^{5,14,22}$ OIIRR was classified based on the severity into: (a) Root surface or cementum resorption accompanied with remodeling; (b) Deep resorption affecting root cementum and the outer layers of dentin accompanied with cementum repair and; (c) Circumferential root resorption with evident root shortening. ${ }^{4}$ Different orthodontic systems such as lingual orthodontics, porcelain orthodontic brackets, and thermoplastic clear aligners were developed as the demand for esthetic orthodontic appliances is increasing rapidly. ${ }^{24}$ As orthodontic clear aligners became more popular, several papers were published reporting their association with OIIRR. These papers varied between in vivo studies, ${ }^{25}$ case reports, ${ }^{26}$ clinical trials, ${ }^{15,16}$ and systematic reviews. ${ }^{9,17}$ In a study published in 2010 by Fowler, it was reported 
Flowchart 1: PRISMA flow diagram
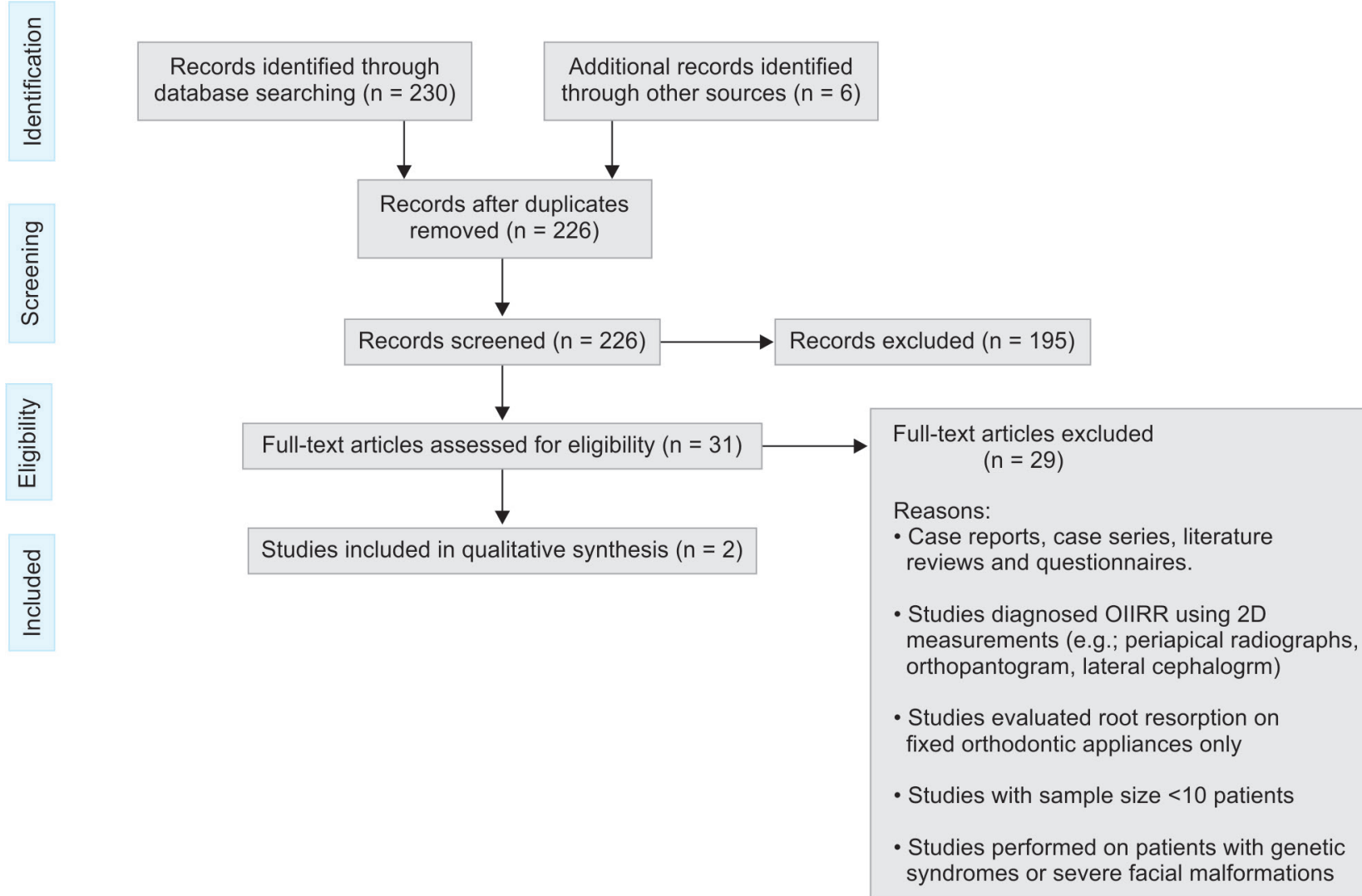

Table 2: Qualitative assessment of study design

\begin{tabular}{llllllll}
\hline Author & Objectives & Times & Sample size & $\begin{array}{l}\text { Sample } \\
\text { randomization }\end{array}$ & $\begin{array}{l}\text { Control } \\
\text { group }\end{array}$ & $\begin{array}{l}\text { Selection } \\
\text { criteria }\end{array}$ & $\begin{array}{l}\text { Total points } \\
\text { (Max 10) }\end{array}$ \\
\hline Barbagallo et al. $^{11}$ & 1 & 2 & 4 & 1 & 1 & 1 & 10 \\
Taylor $^{21}$ & 1 & 0 & 4 & 0 & 1 & 1 & 7 \\
\hline
\end{tabular}

Table 3: Qualitative assessment of methodologic soundness

\begin{tabular}{|c|c|c|c|c|c|}
\hline Author & Appliance type & Force magnitude & $\begin{array}{l}\text { Radiographic } \\
\text { examination before } \\
\text { treatment }\end{array}$ & $\begin{array}{l}\text { Measurement } \\
\text { method of root } \\
\text { resorption }\end{array}$ & $\begin{array}{l}\text { Total points } \\
\text { (Max 7) }\end{array}$ \\
\hline Barbagallo et al. ${ }^{11}$ & 1 & 1 & 0 & 2 & 4 \\
\hline Taylor $^{21}$ & 1 & 0 & 1 & 2 & 4 \\
\hline
\end{tabular}

Table 4: Qualitative Assessment of Data Analysis.

\begin{tabular}{llllll}
\hline Author & Statistical analysis & Error of the method & Data presentation & Variability measures & Total points (Max 4) \\
\hline Barbagallo et al. $^{11}$ & 1 & 0 & 1 & 1 & 3 \\
Taylor $^{21}$ & 1 & 1 & 1 & 1 & 4 \\
\hline
\end{tabular}

Table 5: Level of Evidence and Risk of Bias Assessment

\begin{tabular}{|c|c|c|c|c|c|c|c|c|c|c|}
\hline Author & $\begin{array}{l}\text { Total } \\
\text { Score (\%) }\end{array}$ & $\begin{array}{l}\text { Evidence } \\
\text { Level }\end{array}$ & $\begin{array}{l}\text { Random } \\
\text { Sequence } \\
\text { Generation }\end{array}$ & $\begin{array}{l}\text { Allocation } \\
\text { Concealment }\end{array}$ & $\begin{array}{l}\text { Blinding of } \\
\text { Participants } \\
\text { and Personnel }\end{array}$ & $\begin{array}{l}\text { Blinding of } \\
\text { Outcome } \\
\text { Assessment }\end{array}$ & $\begin{array}{l}\text { Incomplete } \\
\text { Outcome } \\
\text { Data }\end{array}$ & $\begin{array}{l}\text { Selective } \\
\text { Reporting }\end{array}$ & $\begin{array}{l}\text { Other } \\
\text { Bias }\end{array}$ & $\begin{array}{l}\text { Risk } \\
\text { of } \\
\text { Bias }\end{array}$ \\
\hline $\begin{array}{l}\text { Barbagallo } \\
\text { et al. }{ }^{11} \\
(2008)\end{array}$ & $17(80.9 \%)$ & High & Low Risk & High Risk & Low Risk & Low Risk & Low Risk & Low Risk & None & $\begin{array}{l}\text { Low } \\
\text { Risk }\end{array}$ \\
\hline $\begin{array}{l}\text { Taylor } 21 \\
(2016)\end{array}$ & 15 (71.4\%) & High & High Risk & High Risk & High Risk & $\begin{array}{l}\text { Unclear } \\
\text { Risk }\end{array}$ & Low Risk & Low Risk & $\begin{array}{l}\text { High } \\
\text { Risk }\end{array}$ & $\begin{array}{l}\text { High } \\
\text { Risk }\end{array}$ \\
\hline
\end{tabular}

that the maximal root resorption was found in maxillary lateral incisors followed by maxillary central incisors, mandibular lateral incisors, mandibular central incisors, and maxillary canines; while the least affected teeth were mandibular canines. ${ }^{14}$ Several studies evaluated OIIRR using periapical radiographs, orthopantomogram and lateral cephalogram which could have possibly influenced the findings. ${ }^{9114,15,17}$ Meanwhile, milestones in the threedimensional imaging technology were accomplished and, hence, 3D imaging was implemented in the dental practice. 
Association of Orthodontic Clear Aligners with Root Resorption Using Three-dimension Measurements: A Systematic Review

\begin{tabular}{|c|c|c|c|c|c|}
\hline \multicolumn{6}{|c|}{ Table 6: Summary of The Main Findings (PICOS) } \\
\hline Author & Participants & Intervention & Comparison & Outcome & Study Design \\
\hline Barbagallo et al. ${ }^{11}$ & $\begin{array}{l}54 \text { maxillary first } \\
\text { premolars in } 27 \\
\text { patients (15 } \mathrm{F}: 12 \mathrm{M}) \text {. } \\
\text { Mean age was } \\
15 \text { years } 4 \text { months } \\
\text { (range, } 12 \text { years } \\
6 \text { months-20 years } \\
0 \text { months). }\end{array}$ & $\begin{array}{l}\text { Orthodontic } \\
\text { treatment with } \\
\text { clear aligners } \\
\text { (ClearSmile } ₫ \text {, } \\
\text { ClearSmile), light } \\
\text { force }(25 \mathrm{~g}) \text { and } \\
\text { heavy force }(225 \mathrm{~g}) \\
\text { fixed appliances. }\end{array}$ & $\begin{array}{l}\text { Root resorption } \\
\text { among three groups. } \\
\text { In each study group, } \\
\text { ClearSmile }{ }^{\circledR} \text { aligners } \\
\text { (ClearSmile) were } \\
\text { used in one side } \\
\text { of the dental arch. } \\
\text { The contralateral } \\
\text { side served as a } \\
\text { control that received } \\
\text { no intervention in } \\
\text { the first group, light } \\
\text { force fixed appliance } \\
(25 \text { g) in the second } \\
\text { group and heavy } \\
\text { force fixed appliance } \\
\text { group ( } 225 \mathrm{~g} \text { ) in the } \\
\text { third group. }\end{array}$ & $\begin{array}{l}\text { The amount of } \\
\text { root resorption in } \\
\text { ascending order: } \\
\text { control, light force, } \\
\text { clear aligner } \\
\text { then heavy force } \\
\text { appliances of } \\
\text { which all findings } \\
\text { were statistically } \\
\text { significant in relation } \\
\text { to control group } \\
\text { (p<0.001). No } \\
\text { statistical significant } \\
\text { difference was found } \\
\text { between the light } \\
\text { force group and } \\
\text { clear aligners group. }\end{array}$ & $\begin{array}{l}\text { Randomized } \\
\text { Controlled Trial - } \\
\text { Split Mouth Design. }\end{array}$ \\
\hline Taylor $^{21}$ & $\begin{array}{l}60 \text { orthodontic } \\
\text { patients. Mean } \\
\text { age in conventional } \\
\text { and Invisalign } \\
\text { groups was } 22.2 \\
(\mathrm{SD}=11.5) \text { and } \\
19.0(\mathrm{SD}=10.7) \\
\text { years, respectively. }\end{array}$ & $\begin{array}{l}\text { Orthodontic } \\
\text { treatment with } \\
\text { clear aligners } \\
\text { (Invisalign }{ }^{\circledR} \text {, Align } \\
\text { Technology Inc.) and } \\
\text { conventional fixed } \\
\text { edgewise. }\end{array}$ & $\begin{array}{l}\text { Root resorption } \\
\text { among two groups, } \\
\text { Invisalign }{ }^{\circledR} \text { (Align } \\
\text { Technology Inc.) and } \\
\text { conventional fixed } \\
\text { appliance. }\end{array}$ & $\begin{array}{l}\text { Invisalign group } \\
\text { experienced } \\
\text { less apical root } \\
\text { resorption than } \\
\text { conventional fixed } \\
\text { appliance }(p<0.05) \text {. }\end{array}$ & $\begin{array}{l}\text { Retrospective } \\
\text { Cohort Study. }\end{array}$ \\
\hline
\end{tabular}

Images produced by 3D measurements, when compared to 2D measurements, had a rapid scanning time (10 to 70 seconds) and were associated with progressive accuracy and less imaging artifact. ${ }^{26,27}$ Moreover, 3D measurements aid significantly in the orthodontic field by diagnosing craniofacial abnormalities such as facial asymmetries, functional shifts, and canted occlusal plane. ${ }^{28-30}$ In a study published by Gribel et al., they recommended using CBCT craniometric measurements computed by the 3D cephalometric module as a quantitative diagnostic tool owing to its outstanding accuracy. ${ }^{31}$ Furthermore, there is evidence that using 2D measurements to evaluate root resorption is inferior to 3D measurements in terms of accuracy and reliability. ${ }^{18,32,33}$ Therefore, studies that used 3D measurements only were included.

\section{Description of Included Studies}

- The randomized controlled trial published in 2008 by Barbagallo et al. ${ }^{11}$ quantified the amount of root resorption associated with orthodontic clear aligners (ClearSmile ${ }^{\circledR}$, ClearSmile, Woollongong, Australia) and compared it to a no-treatment control group, light force (25 g) and high force (225 g) fixed appliances. The amount of root resorption was measured using microcomputed-tomography and the measurement unit was the cube root of voxels (pixels) which is equivalent to $0.01709 \mathrm{~mm}$. The least root resorption was found in the control group with a mean resorption of 4.913 pixels ( $\mathrm{SE}=1.786$ ) followed by the light force group which had root resorption five times than the control group with a mean of 26.182 pixels ( $\mathrm{SE}=1.786$ ). Also, clear aligners group (ClearSmile ${ }^{\circledR}$, ClearSmile) had mean root resorption of 29.034 pixels ( $\mathrm{SE}=0.799$ ), that is six times more than the control group. The highest root resorption was in the heavy force group (225 g) which was nine times more than the control group (mean 46.447 pixels, $\mathrm{SE}=1.786$ ). A statistically significant difference $(\mathrm{P}<0.001)$ was found between all groups except for the difference between clear aligners and light-force fixed appliances, that was statistically insignificant $(p=0.947)$. Although the study lacked pre-operative radiographs as well as allocation concealment, it was of high methodologic quality $(80.9 \%)$ and had a low risk of bias.

- The retrospective cohort study published by Taylor ${ }^{21}$ in 2016, quantified the amount of root resorption in clear aligners (Invisalign ${ }^{\circledR}$, Align Technology Inc., San Jose, CA, USA) and compared it with conventional fixed appliances using CBCT. Participants in the clear aligner group experienced root resorption less than the participants in the fixed appliance group ( $p$ <.05). The mean root resorption experienced by the clear aligner and conventionally fixed appliance groups were $0.44 \mathrm{~mm}(\mathrm{SD}=0.12)$ and $1.13 \mathrm{~mm}$ $(\mathrm{SD}=0.18)$, respectively. Evaluating the methodologic quality, this paper had a high level of evidence (71.4\%). However, it was labeled as of high risk of bias owing to the lack of randomization, allocation concealment, 
blinding and specification of used force magnitude measurement. Other limitations to this study were the lack of description of finishers' quality as well as not measuring the amount of apical displacement in both groups. Summary of both included studies based on participants, intervention, comparison, outcome and study design (PICOS) is presented in (Table 6).

\section{Strength and Limitations}

A major strength of this systematic review is employing strict selection criteria to ensure only papers with a high level of evidence be taken into consideration. Only two out of 226 studies were eligible for qualitative synthesis; this also reflects the scarcity of high-quality studies on this topic.

\section{CONCLUSION}

Based on the available studies with high level of evidence in the literature, we conclude that orthodontic clear aligners are non-inferior to light-force fixed orthodontic appliances and superior to heavy-force fixed orthodontic appliances in terms of the risk for developing apical root resorption. However, only one randomized control trial and one cohort study met this systematic review's selection criteria. Therefore, randomized controlled trials employing meticulous methodology, sample selection criteria, 3D measurements of root resorption and control of possible sources of bias are needed to formulate a solid evidence-based conclusion.

\section{CLINICAL SIGNIFICANCE}

Based on the findings reported in this systematic review, orthodontists can be more assured about the low-risk of OIIRR associated with clear aligners compared to other orthodontic treatment modalities, and it remains up to the practitioner's assessment to select the appropriate treatment on a case by case basis.

\section{REFERENCES}

1. Topkara A, Karaman AI, Kau CH. Apical root resorption caused by orthodontic forces: A brief review and a long-term observation. Eur J Dent. 2012;6(4):445-453.

2. Fuss Z, Tsesis I, Lin S. Root resorption--diagnosis, classification and treatment choices based on stimulation factors. Dent Traumatol. 2003;19(4):175-482.

3. Jiménez Montenegro VC, Jones A, Petocz P, Gonzales C, Darendeliler MA. Physical properties of root cementum: Part 8. Root resorption after the application of light and heavy extrusive orthodontic forces: A microcomputed tomography study. Am J Orthod Dentofac Orthop. 2012;141(1):7-8.

4. Brezniak N, Wasserstein A. Orthodontically induced inflammatory root resorption. Part I: the basic science aspects. The Angle Orthodontist. 2002 Apr;72(2):175-9.
5. Hendrix I, Carels C, Kuijpers-Jagtman a M, Van 'T Hof M. A radiographic study of posterior apical root resorption in orthodontic patients. Am J Orthod Dentofacial Orthop. 1994;105(4):345-349.

6. Janson GRP, De Luca Canto G, Rodrigues Martins D, Castanha Henriquesand JF, De Freitas MR. A radiographic comparison of apical root resorption after orthodontic treatment with 3 different fixed appliance techniques. Am J Orthod Dentofac Orthop. 2000;118(3):262-273.

7. Lund H, Gröndahl K, Hansen K, Gröndahl H-G. Apical root resorption during orthodontic treatment. Angle Orthod. 2012;82(3):480-487.

8. Liu Y, Guo H. [Comparison of root resorption between selfligating and conventional brackets using cone-beam CT] Shanghai Kou Qiang Yi Xue. 2016;25(2):238-241.

9. Roscoe MG, Meira JBC, Cattaneo PM. Association of orthodontic force system and root resorption: A systematic review. Am J Orthod Dentofac Orthop. 2015;147(5):610-626.

10. DiBiase AT, Woodhouse NR, Papageorgiou SN, Johnson N, Slipper C, Grant J, et al. Effect of supplemental vibrational force on orthodontically induced inflammatory root resorption: A multicenter randomized clinical trial. Am J Orthod Dentofac Orthop. 2016;150(6):918-927.

11. Barbagallo LJ, Jones AS, Petocz P, Darendeliler MA. Physical properties of root cementum: Part 10. Comparison of the effects of invisible removable thermoplastic appliances with light and heavy orthodontic forces on premolar cementum. A microcomputed-tomography study. Am J Orthod Dentofac Orthop. 2008;133(2):218-227.

12. King AD, Turk T, Colak C, Elekdag-Turk S, Jones AS, Petocz $P$, et al. Physical properties of root cementum: Part 21. Extent of root resorption after the application of $2.5^{\circ}$ and $15^{\circ}$ tips for 4 weeks: A microcomputed tomography study. Am J Orthod Dentofac Orthop. 2011;140(11):e299-305.

13. Jiménez Montenegro VC, Jones A, Petocz P, Gonzales C, Darendeliler MA.Physical properties of rootcementum:Part22. Root resorption after the application of light and heavy extrusive orthodontic forces: A microcomputed tomography study. Am J Orthod Dentofac Orthop. 2012;141(1):1-4.

14. Fowler B. A comparison of root resorption between Invisalign treatment and contemporary orthodontic treatment. [A Thesis Presented to The Faculty of The USC Graduate School University Of Southern California]. 2010;(May).

15. Gay G, Ravera S, Castroflorio T, Garino F, Rossini G, Parrini $\mathrm{S}$, et al. Root resorption during orthodontic treatment with Invisalign ${ }^{\circledR}$ : a radiometric study. Prog Orthod. 2017;18(1):12.

16. Iglesias-Linares A, Sonnenberg B, Solano B, Yañez-Vico RM, Solano E, Lindauer SJ, et al. Orthodontically induced external apical root resorption in patients treated with fixed appliances vs removable aligners. Angle Orthod. 2017;87(1): 3-10.

17. Elhaddaoui R, Qoraich HS, Bahije L, Zaoui F. Orthodontic aligners and root resorption: A systematic review. Vol. 15, International Orthodontics. 2017. p. 1-12.

18. Agrawal JM, Agrawal MS, Nanjannawar LG, Parushetti AD. CBCT in orthodontics: The wave of future. J Contemp Dent Pract. 2013;14(1):153-157.

19. Moher D, Liberati A, Tetzlaff J, Altman DG, Altman D, Antes $G$, et al. Preferred reporting items for systematic reviews and meta-analyses: The PRISMA statement. PLoS Med. 2009;6(7).

20. Higgins JPT, Green S (editors). Cochrane Handbook for Systematic Reviews of Interventions Version 5.1.0 [updated 
March 2011]. The Cochrane Collaboration, 2011. Available from www.handbook.cochrane.org.

21. Taylor J . Metcalf. Comparison of external apical root resorption in Class I subjects treated with Invisalign and conventional orthodontics A CBCT analysis [A Thesis Presented to the Faculty of Graduate Education of Saint Louis University]. 2016;28-45.

22. Hartsfield JK, Everett ET, Al-Qawasmi RA. Hartsfield Jr JK, Everett ET, Al-Qawasmi RA. Genetic factors in external apical root resorption and orthodontic treatment. Critical Reviews in Oral Biology \& Medicine. 2004 Mar;15(2):115-122. Crit Rev Oral Biol Med. 2004;15(2):115-122.

23. Brezniak N, Wasserstein A. Orthodontically Induced Inflammatory Root Resorption. Part II: The Clinical Aspects. 2009;72(2):1-2.

24. Lopes Filho H, Maia LEG, Araújo MVA, Ruellas ACO. Lopes Filho H, Maia LE, Araújo MV, Ruellas AC. Influence of optical properties of esthetic brackets (color, translucence, and fluorescence) on visual perception. American Journal of Orthodontics and Dentofacial Orthopedics. 2012 Apr 1;141(4):460-467. Am J Orthod Dentofac Orthop. 2012;141(4):460-467.

25. Sombuntham NP, Songwattana S, Atthakorn P, Jungudomjaroen S, Panyarachun B. Early tooth movement with a clear plastic appliance in rats. Am J Orthod Dentofac Orthop. 2009;136(1): 75-82.

26. Cassetta M, Altieri F, Pandolfi S, Giansanti M. The combined use of computer-guided, minimally invasive, flapless corticotomy and clear aligners as a novel approach to moderate crowding: A case report. Korean J Orthod. 2017;47(2):130-141.

27. Scarfe WC, Farman AG, Sukovic P. Clinical Applications of Cone-Beam Computed Tomography in Dental Practice. J Can Dent Assoc. 2006;72(1):75-80.
28. Katsumata A, Fujishita M, Maeda M, Ariji Y, Ariji E, Langlais RP. Katsumata A, Fujishita M, Maeda M, Ariji Y, Ariji E, Langlais RP. 3D-CT evaluation of facial asymmetry. Oral Surgery, Oral Medicine, Oral Pathology, Oral Radiology, and Endodontology. 2005 Feb 1;99(2):212-20. Oral Surgery, Oral Med Oral Pathol Oral Radiol Endodontology. 2005;99(2): 212-220.

29. Maeda M, Katsumata A, Ariji Y, Muramatsu A, Yoshida K, Goto S, et al. Maeda M, Katsumata A, Ariji Y, Muramatsu A, Yoshida K, Goto S, Kurita K, Ariji E. 3D-CT evaluation of facial asymmetry in patients with maxillofacial deformities. Oral Surgery, Oral Medicine, Oral Pathology, Oral Radiology, and Endodontology. 2006 Sep 1;1. 2006;102(3):382-390.

30. Tuncer BB, Ataç MS, Yüksel S. Tuncer BB, Ataç MS, Yüksel S. A case report comparing 3-D evaluation in the diagnosis and treatment planning of hemimandibular hyperplasia with conventional radiography. Journal of Cranio-Maxillofacial Surgery. 2009 Sep 1;37(6):312-319. J Cranio-Maxillofacial Surg. 2009;37(6):312-319.

31. Gribel BF, Gribel MN, Frazão DC, McNamara JA, Manzi FR. Accuracy and reliability of craniometric measurements on lateral cephalometry and 3D measurements on CBCT scans. Angle Orthod. 2011;81(1):28-37.

32. Durack C, Patel S, Davies J, Wilson R, Mannocci F. Diagnostic accuracy of small volume cone beam computed tomography and intraoral periapical radiography for the detection of simulated external inflammatory root resorption. 2011;c: 136-147.

33. Dudic A, Giannopoulou C, Leuzinger M, Kiliaridis S. Detection of apical root resorption after orthodontic treatment by using panoramic radiography and cone-beam computed tomography of super-high resolution. American Journal of Orthodontics and Dentofacial. 2009;1;135(4):434-437. 